332.133

\title{
EVALUATION OF THE EFFECTIVENESS OF REFORMS IN THE POWER POSITIONS OF INSTITUTIONALISM
}

• . емиколенов

A. V. Semikolenov

« зиром энерго», г. оскв

лючевые слов : электроэнергетик ; реформ электроэнергетики; экономические

институты; институцион лизм

Key words: power; electricity reform; economic institutions; institutionalism

оссийск я отр сль электроэнергетики с конц 1990-х гг. и до н стоящего времени н ходится в перм нентном состоянии реорг низ ции. то проявляется в обр зов нии новых комп ний, внесении изменений в орг низ ционно-пр вовую форму существующих комп ний, в том числе присоединения, слияния, поглощения и др. роме этого, отличительной чертой российской электроэнергетики можно н зв ть ликвид цию или б нкротство предприятий отр сли с последующим перемещением к пит л в более рент бельные сферы деятельности, обр зов ние холдингов.

зн ч льно потребность в реформиров нии и реорг низ ции электроэнергетики был продиктов н преимущественно техническими ф ктор ми, т кими к к специфик системы н цион льного электросн бжения, в числе которых нер вномерное р змещение генерирующих мощностей, т кже существенн я з висимость в большинстве регионов от перетоков электроэнергии внутри системы.

д льнейшем существенное влияние ок з ли ф кторы экономико-орг низ ционного $\mathrm{x}$ р ктер, детерминиров нные отсутствием н л женной и эффективной системы оптовой торговли электроэнергией н межрегион льном уровне, т кже неподготовленность орг нов вл сти федер льного зн чения осуществлять эффективное регулиров ние рынк межсистемных перетоков. условиях сложившихся тенденций существов л высок я вероятность угрозы монополизм в регион х с избытком энергетических мощностей и последующей дезорг низ цией межсистемных перетоков. целью сохр нения р ботоспособности н цион льной электроэнергетики с учетом имеющихся нег тивных ф кторов возникл идея объединения всех отр слевых упр вленческих функций в единую холдинговую структуру, с одновременным выведением крупных генерирующих мощностей и межсистемных сетей из сост в энергосн бж ющих орг низ ций н регион льном уровне [1].

н чительные институцион льные преобр зов ния, которые 3 тронули российскую электроэнергетику з последнее десятилетие, были преимущественно н целены н сферу внедрения в отр сли рыночных мех низмов, повышения функцион льности и инвестиционной привлек тельности ведущих энергетических комп ний. ри этом н ч лом ук з нного процесс спр ведливо можно счит ть 2001 г., в котором происходящие тр нсформ ционные процессы в естественно-монопольных отр слях многих стр н, т кже преобр зов ния в экономике оссии, обусловили н ч ло широком сшт бной и структурно сложной реформы.

одтверждением этого ф кт является пост новление р вительств « реформиров нии электроэнергетики оссийской едер ции» [2], которое регл ментирует ключевые н пр вления и первостепенные з д чи реформиров ния. нный документ з декл риров л переход электроэнергетической отр сли к режиму устойчивого $\mathrm{p}$ звития н основе применения прогрессивных технологий и использов ния рыночных принципов функциониров ния, которые г р нтируют потребителям н дежное и экономически обоснов нное удовлетворение их пл тежеспособного спрос н тепловую и электрическую энергию в условиях 
кр ткосрочного и долгосрочного периодов времени. ким обр зом, д нный кт уст н влив л основные н пр вления в сфере рыночных тр нсформ ций электроэнергетической отр сли

роцесс либер лиз ции отр сли в оссии должен был решить т кие приоритетные 3 д чи, к к формиров ние конкурентных рынков прод жи электроэнергии, сокр щение м сшт бов госуд рственного регулиров ния упр вленческих процессов в электроэнергетике, выделение монопольных и потенци льно конкурентных видов деятельности ук з нной отр сли, полную ликвид цию проявлений перекрестного субсидиров ния, что т кже было отр жено в соответствующей нергетической стр тегии того период [3].

льнейший процесс реформиров ния, продолж ющийся в 2003 г., 3 пустил м сшт бную реструктуриз цию крупнейшего н цион льного монополист электроэнергетической отр сли стр ны - « оссии» [4] н корпор тивном уровне. 2008 г. процесс реструктуриз ции отр сли в целом был з вершен. ходе д нной реструктуриз ции из сост в

был выделен ее б зовый мех низм в виде с мостоятельно функционирующих профильных комп ний в р зрезе т ких видов деятельности [5]: генерирующие комп нии, объединившие в своем сост ве генерирующие ктивы (производственные); энергосбытовые комп нии, прод ющие электроэнергию потребителям; сетевые комп нии, включ ющие в себя р спределительные электрические сети м гистр льного и регион льного свойств; субъекты упр вления опер тивно-диспетчерской деятельностью; коммерческ я инфр структур оптового рынк .

ервые результ ты реформиров ния российской электроэнергетики в целом прошли с учетом н копленного з рубежного опыт ( еликобрит ния) и з тронули процессы выделения конкурентных видов деятельности, т ких к к генериров ние электроэнергии и ее сбыт от естественно-монопольных (перед ч электроэнергии по сетям и диспетчериз ция). ри этом м гистр льные электросети перешли в подчинение федер льной сетевой комп нии; p спределительные сети были целиком интегриров ны в р спределительные сетевые комп нии межрегион льного уровня ( ); функции диспетчерских упр влений в регион х отошли к общероссийскому системному опер тору. $\mathrm{p}$ мк х д нных тр нсформ ционных процессов был сформиров н коммерческ я инфр структур по орг низ ции торговли электроэнергией и мощностью н оптовом рынке.

ледует отдельно выделить т кую специфическую особенность институцион льных преобр зов ний электроэнергетики оссии, к к полное р зделение всех видов деятельности в отр сли н конкурентные и естественно-монопольные. к, н 3 конод тельном уровне было регл ментиров но, что с 1 преля 2006 г. юридические лиц и индивиду льные предприним тели не уполномочены совмещ ть в процессе своей хозяйственной деятельности естественно-монопольные и потенци льно конкурентные виды деятельности [6]. пеци листы отмеч ют, что пятилетний процесс реформиров ния электроэнергетики к 1 июля 2008 г. был пр ктически 3 вершен, одн ко нельзя ск з ть с уверенностью, что с изменением структуры российской электроэнергетики были целиком и полностью решены все пост вленные в ходе реформы 3 д чи.

p мк х д нного исследов ния уместным предст вляется проведение н лиз результ тов реструктуриз ции и демонополиз ции н цион льной электроэнергетической отр сли в сост ве теории институцион лизм . остул ты теории институцион лизм предпол г ют, что в р мк х институцион льной структуры обществом может созд в ться систем определенных стимуляторов эффективности деятельности экономических гентов н микроэкономическом уровне. 3 этого вытек ет, что любые изменения в институцион льной структуре приводят к повышению или снижению уровня эффективной деятельности экономических гентов. ким обр зом, сдел ть к чественную оценку процесс институцион льных преобp зов ний возможно с помощью проведения систем тического мониторинг и н лиз изменений выбр нных п р метров.

ереходный период преобр зов ний электроэнергетики , связ нный с моментом созд ния « оссии», х р ктеризуется тр нсформ цией из единой госуд рственной системы с центр лизов нным упр влением в новую структуру, состоящую из кциониров нных и ч стично прив тизиров нных энергетических комп ний федер льного и регион льного зн чения. отличие от существов вшей структуры отр сли в 2000 г., котор я $\mathrm{x}$ р ктеризов л сь доминиров нием госуд рственной собственности и дост точно высоким уровнем госуд рственного контроля, новой структуре х р ктерн тр нсформ ция 6 зовых институтов экономики в структуре институцион льной м трицы электроэнергетики, которую прошл отр сль в ходе реформиров ния в период с 2003 г. по н стоящее время (т блиц ). 
нституцион льные преобр зов ния в электроэнергетической отр сли оссии

в процессе реформиров ния (2003-2011 г2.)

\begin{tabular}{|c|c|c|c|}
\hline \multirow{2}{*}{$\begin{array}{l}\text { зовый уровень } \\
\text { экономических } \\
\text { институтов }\end{array}$} & \multirow{2}{*}{$\begin{array}{c}\text { ритерии оценив ния } \\
\text { процессов } \\
\text { тр нсформ ции } \\
\text { отр сли } \\
\end{array}$} & \multicolumn{2}{|c|}{ истем тиз ция видов экономических институтов } \\
\hline & & о 2003 г. & н ч ло 2011 г. \\
\hline $\begin{array}{c}\text { нституты, } \\
\text { отр ж ющие } \\
\text { степень } \\
\text { использов ния } \\
\text { пр в } \\
\text { собственности }\end{array}$ & $\begin{array}{c}\text { ч стие } \\
\text { госуд рств }, \\
\text { прямо и косвенно, } \\
\text { в к пит л х } \\
\text { комп ний } \\
\text { с огр ничениями } \\
\text { по использов нию } \\
\text { собственности }\end{array}$ & $\begin{array}{l}\text { - оля прямого уч стия } \\
\text { госуд рств свыше } 50 \% \\
\text { ( } \quad \text { оссии» }-52 \%) \\
\text { - от льный } \\
\text { госуд рственный } \\
\text { контроль н д сферой } \\
\text { применения } \\
\text { собственности }\end{array}$ & $\begin{array}{l}\text { p ктеристик по ключевым вид м } \\
\text { деятельности: } \\
\text { испетчериз ция: прямое уч стие госуд р- } \\
\text { ств с долей } 100 \% \text {; тот льный гос. контроль } \\
\text { в сфере применения собственности. } \\
\text { еред ч : прев лирует прямое уч стие } \\
\text { госуд рств с долей в среднем свыше } 60 \% \text {; } \\
\text { единоличный контроль госуд рств в сфере } \\
\text { применения собственности. } \\
\text { енер иия: } \\
\text { - косвенное уч стие госуд рств в оптовых } \\
\text { генерирующих комп ниях с долей в среднем } \\
\text { около } 30 \% \text {; } \\
\text { - косвенное уч стие госуд рств в генери- } \\
\text { рующих комп ниях н территори льном } \\
\text { уровне сост вляет в среднем менее } 7 \% \text {; } \\
\text {-н личие огр ничения гос. контроля в сфере } \\
\text { применения собственности. } \\
\text { быт: огр ничение гос. контроля в сфере } \\
\text { применения собственности, доля в среднем } \\
\text { менее } 7 \% ;\end{array}$ \\
\hline \multirow[t]{2}{*}{$\begin{array}{c}\text { нституты, } \\
\text { формирующие } \\
\text { процессы } \\
\text { р спределения } \\
\text { ресурсов } \\
\text { и продуктов } \\
\text { производств }\end{array}$} & $\begin{array}{c}\text { рг низ ция госу- } \\
\text { д рственного упр вле- } \\
\text { ния и системы норм - } \\
\text { тивно-пр вового регу- } \\
\text { лиров ния процессов } \\
\text { приобретения, } \\
\text { использов ния и отчу- } \\
\text { ждения имуществ и } \\
\text { продукции роизводств } \\
\text { (р бот, услуг) }\end{array}$ & $\begin{array}{l}\text { - роведенным процесс м кцио- } \\
\text { ниров ния и ч стичной прив ти- } \\
\text { з ции орг низ ций электроэнер- } \\
\text { гетики свойственно преобл д ние } \\
\text { уч стия госуд рств в их собст- } \\
\text { венности и упр влении } \\
-\quad \text { т рт прив тиз ции и р звития } \\
\text { конкуренции в сфер х производ- } \\
\text { ств , сбыт и ок } 3 \text { ния услуг }\end{array}$ & $\begin{array}{l}\text { - рив тиз цию орг низ ций электроэнерге- } \\
\text { тики в целом можно счит ть } 3 \text { вершенной } \\
-\quad \text { стичное сохр нение уч стия осуд рств } \\
\text { в упр влении только в естественно- } \\
\text { монопольных вид х деятельности и энерге- } \\
\text { тических комп ниях, включ ющих в число } \\
\text { кционеров предст вителей госуд рств } \\
-\quad \text { охр нение регулиров ния госуд рством } \\
\text { цен и т рифов }\end{array}$ \\
\hline & $\begin{array}{c}\text { личие } \\
\text { огр ничительных } \\
\text { б рьеров и рыч гов } \\
\text { принуждения }\end{array}$ & $\begin{array}{l}\text { - роведение тр нсформиров - } \\
\text { ния рынк электрической энер- } \\
\text { гии оптового тип н федер ль- } \\
\text { ном уровне в полноценный } \\
\text { рынок электроэнергии } \\
\text { конкурентно-оптового тип } \\
\text { с последующим формиров нием } \\
\text { эффективных розничных рынков } \\
-\quad \text { беспечение тот льного коор- } \\
\text { диниров ния пл нов и инвести- } \\
\text { ционных проектов электроэнерге- } \\
\text { тических комп ний }\end{array}$ & $\begin{array}{l}\text { вершены тр нсформ ционные процессы } \\
\text { н действующем оптовом рынке электри- } \\
\text { ческой энергии н федер льном уровне с } \\
\text { переходом его в полноценный конкурентный } \\
\text { оптовый рынок электрэнергии, с д льней- } \\
\text { шим созд нием розничных рынков } \\
-\quad \text { существление координиров ния пл нов и } \\
\text { инвестиционных проектов энергетических } \\
\text { комп ний путем р зр ботки согл сов - } \\
\text { тельных процедур в р мк х энергетической } \\
\text { стр тегии госуд рств , прогр мм р звития } \\
\quad \text { оссии } \\
\text { озд ние бл гоприятных условий для } \\
\text { существов ния рынк электроэнергии опто- } \\
\text { вого тип в предел х единой рыночной } \\
\text { сферы н европейской территории оссии, } \\
\text { н р ле и в ибири, кроме изолиров нных } \\
\text { энергосистем, относящихся к этим террито- } \\
\text { риям } \\
\end{array}$ \\
\hline $\begin{array}{c}\text { нституты } \\
\text { гр жд нско- } \\
\text { пр вового } \\
\text { договор } \\
\text { (контр кт ции) }\end{array}$ & $\begin{array}{c}\text { ормиров ние } \\
\text { действенного порядк } \\
3 \text { ключения гр жд н- } \\
\text { скопр вовых договоров } \\
\text { и согл сов ния тр н- } \\
\text { с кций, свободный } \\
\text { выбор контр гент } \\
\end{array}$ & $\begin{array}{l}\text { - } \quad \text { звитие контр ктных } \\
\text { отношений в плоскости } \\
\text { оптового рынк } \\
\text { - егулиров ние н госуд рствен- } \\
\text { ном уровне рынков оптового } \\
\text { и розничного типов }\end{array}$ & $\begin{array}{l}\text { - от льное внедрение н оптовом рынке } \\
\text { контр ктных отношений } \\
\text { - озможность выход н оптовый рынок } \\
\text { крупных потребителей } \\
\text { - егулиров ние госуд рством рынков } \\
\text { оптового и розничного типов }\end{array}$ \\
\hline $\begin{array}{c}\text { нституты, } \\
\text { детерминирующие } \\
\text { применение к дров }\end{array}$ & $\begin{array}{c}\text { конность } \\
\text { применения норм } \\
\text { по выполнению } \\
\text { трудовых } \\
\text { обяз нностей } \\
\text { и порядк } \\
\text { опл ты труд }\end{array}$ & $\begin{array}{l}\text { - спользов ние н емного труд , } \\
\text { основ нного н контр ктных } \\
\text { вз имоотношениях р ботод теля } \\
\text { и р ботник с элемент ми регули- } \\
\text { ров ния госуд рством трудовых } \\
\text { отношений с руководителями } \\
\text { энергетических комп ний, в } \\
\text { которых преобл д ет доля госу- } \\
\text { д рственной собственности } \\
\end{array}$ & $\begin{array}{l}\text { - спользов ние н емного труд, , основ нно- } \\
\text { го н контр ктных вз имоотношениях р бо- } \\
\text { тод теля и р ботник с элемент ми регули- } \\
\text { ров ния госуд рством трудовых отношений } \\
\text { н уровне руководителя энергетических } \\
\text { комп ний со стороны кционеров (в том } \\
\text { числе предст вителей госуд рств ) }\end{array}$ \\
\hline $\begin{array}{c}\text { нститут } \\
\text { по регуляции } \\
\text { вз имоотношений } \\
\text { экономического } \\
\text { х р ктер } \\
\text { (институт } \\
\text { обр тных связей) }\end{array}$ & $\begin{array}{c}\text { тсутствие (присутст- } \\
\text { вие) регулятивных } \\
\text { рыч гов воздействия н } \\
\text { госуд рственном } \\
\text { уровне и введение } \\
\text { огр ничений экономи- } \\
\text { ческого х р ктер для } \\
\text { фин нсово- } \\
\text { хозяйственной } \\
\text { деятельности } \\
\text { субъектов отр сли }\end{array}$ & $\begin{array}{l}\text { - еновое (т рифное) } \\
\text { регулиров ние госуд рством } \\
\text { в отношении рент бельности } \\
\text { энергетических комп ний } \\
\text { - спользов ние перекрестного } \\
\text { субсидиров ния }\end{array}$ & $\begin{array}{l}\text { - зделение видов деятельности н естест- } \\
\text { венно-монопольные и конкурентные, про- } \\
\text { цесс одновременного снижения уровня } \\
\text { регулиров ния госуд рством в конкурентном } \\
\text { секторе } \\
- \text { роведение полной либер лиз ции н } \\
\text { рынке электроэнергии и мощности с } 1 \text { янв ря } \\
2011 \text { г. } \\
-\quad \text { бережение регулиров ния госуд рством } \\
\text { ценовой (т рифной) политики путем поэт п- } \\
\text { ного изменения системы т рифообр зов ния } \\
- \text { рименение перекрестного } \\
\text { субсидиров ния }\end{array}$ \\
\hline
\end{tabular}

№ 5, 2015

ефть и Г 3

143 
ходе институцион льных преобр зов ний необходимо учитыв ть, что электроэнергетическ я отр сль для т кой стр ны, к к оссия, весьм зн чим с позиций ее соци льноэкономического р звития и в контексте ст бильного обеспечения н цион льной безоп сности, в связи с чем преобр зов ния в отр сли необходимо проводить с возможностью н ли3 влияния н другие соци льно зн чимые сферы н родного хозяйств .

числе гл венствующих ф кторов, сдержив ющих деловую ктивность энергетических комп ний, были обозн чены отсутствие или полн я изношенность оборудов ния и остр я нехв тк фин нсовых средств. ри этом результ ты проверок предприятий продемонстриров ли в р вной степени один ковые результ ты для 2008 г. (то есть год оконч ния основного эт п реформы) и для 2010 г. (период , в котором произошл тр нсформ ция институт ч стной собственности), полное отсутствие положительных изменений [8].

2008 г. в к честве гл вного препятствия, сдержив ющего д льнейший экономический рост, был износ н уровне $53 \%$ и отсутствие оборудов ния. охож я ситу ция происходил и с фин нсовыми средств ми в электроэнергетической отр сли. ри этом следует помнить, что 2008 г. является годом н ч л фин нсового кризис, поэтому тр ктов ть снижение пок 3 теля фин нсовых средств следует с позиций ухудшения общеэкономической дин мики.

н лиз приведенных ф кторов позволяет с уверенностью утвержд ть, что проведенные пр вительством тр нсформ ционные преобр зов ния институцион льной среды электроэнергетической отр сли не сформиров ли бл гоприятных условий для рост эффективности деятельности электроэнергетических комп ний. сновной причиной этому послужило отсутствие проведения к чественного системного институцион льного н лиз, игнориров ние целого комплекс в жнейших ф кторов исторического, политического, соци льного и экономического зн чений.

овременный период институцион льных преобр зов ний в электроэнергетике х $\mathrm{p}$ ктеризуется некоторыми попытк ми переосмысления результ тов реформиров ния отр сли и проведением р зностороннего н лиз допущенных ошибок. езусловным является с м ф кт острой необходимости проведения реформиров ния структуры отр сли н тот момент, усовершенствов ние деятельности и эффективности менеджмент в энергетических комп ниях, которые т кже нельзя было н зв ть соответствующими соци льно-экономическому p звитию стр ны и ее курсу н рыночные преобр зов ния.

ким обр зом, можно сдел ть вывод, что современное состояние институцион льных преобр зов ний в электроэнергетике и основн я ее проблем тик были сформиров ны под влиянием мирового фин нсового кризис и последов вшей $з$ ним ст гн ции мирового хозяйств, но в то же время д нные ф кторы способствов ли формиров нию нового взгляд н сущность и роль госуд рств в р звитии электроэнергетической отр сли. месте с тем поспешность и непродум нность проведенных реформ обосновыв ет необходимость глубоких исследов ний в институцион льной сфере для использов ния опыт предыдущих периодов в перспективном р звитии стр ны.

6. едер льный 3 кон от 26 м рт 2003 г. № 36- « б особенностях функциониров ния электроэнергетики в переходный период и о внесении изменений в некоторые 3 конод тельные кты оссийской едер ции и призн нии утр тившими силу некоторых з конод тельных ктов оссийской едер ции в связи с принятием едер льного 3 кон « б электроэнергетике» (п. 14 ст. 6) [ лектронный ресурс]. - ежим доступ : http://www.rg.ru/2008/08/26/energdok.html

7. pюх нов . . ех низм регулиров ния деятельности естественных монополий в электроэнергетике оссии. - овосибирск:, 2011.

ведения об втор $x$

емиколенов ртем икторович, генер льный директор "зиром энерго», г. оскв, тел. 8(495)4284560,e-mail: info@adm.energo.gazprom.ru

Information about the authors

Semikolenov A. V., general director of «Gazprom energo», Moskva, phone: 8(495)4284560, e-mail: info@adm.energo.gazprom.ru
} 